\title{
Choroidal malignant melanoma in association with oculodermal melanocytosis in a black patient
}

\author{
A F Bordon, M L Wray, R Belfort, I W McLean, M Burnier
}

Oculodermal melanocytosis (ODM) is a congenital melanocytic hyperpigmentation of the face and ocular tissues. The eponym naevus of Ota as described by Ota ${ }^{1}$ has been used interchangeably with ODM and ocular melanosis $(\mathrm{OM})$ in many reported cases. The original definition by Ota included patients with and without ocular involvement. For these reasons, we will refer to the term oculodermal melanocytosis, as suggested by Fitzpatrick ${ }^{2}$ to describe this patient's condition.

\section{Case report}

A 65-year-old black woman native of Brazil complained about painless decreased vision in her right eye for 5 months. Her past ocular history revealed a dark pigmentation of her right periocular skin and sclera. She stated that the pigmentation was present since birth with a noticeable increase during puberty. The patient's family history as well as her past medical history were unremarkable. The external examination revealed hyperpigmentation of her right periocular skin. The visual acuity with the best correction was hand movements in the right eye. The slit-lamp examination showed in the right eye pigmentation in all four quadrants of the sclera and episclera as well as in the lid margin (Fig 1). The lens had a $2+$ nuclear opacity and a $2+$ posterior subcapsular cataract. Her left eye was unremarkable except for a $2+$ nuclear opacity of the lens. The intraocular pressure was $12 \mathrm{~mm} \mathrm{Hg}$ in both eyes. Funduscopic findings revealed a

Retina Associates, 100 Charles River Plaza, 2nd Floor, Boston, MA 02114, USA

A F Bordon

M L Wray

R Belfort

I W McLean

M Burnier

Correspondence to:

Dr A F Bordon,

Departamento de

Oftalmologia, Escola Paulista de Medicina, Rua Botucatú, 820, Sao Paulo, SP, Brazil 04043 .

Accepted for publication 5 September 1994

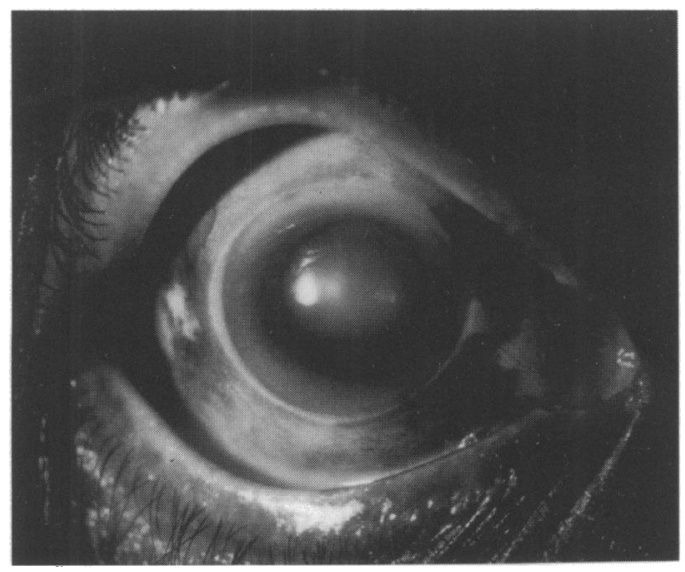

Figure 1 Slit-lamp photography of the patient's right eye showing the pigmentation in all four quadrants of the sclera and in the lid margin as well as a dark pigmentation is seen involving the periocular skin. retinal detachment on the temporal side extending superiorly and inferiorly secondary to a dark choroidal mass that came towards the vitreous cavity. The left fundus was unremarkable. The B scan revealed a mushroom-shaped choroidal mass with partial retinal detachment in accordance with malignant melanoma. A medical examination, including liver enzyme studies, complete blood cell count, and chest $x$ ray, revealed no evidence of metastasis. According to these findings and because of the large size of the tumour an uncomplicated enucleation was performed. The pathological findings showed the sclera diffusely pigmented and transillumination revealed an oval shadow on the superior temporal quadrant. After the eye was opened, a heavily pigmented choroidal tumour measuring $16 \times 10 \times 8 \mathrm{~mm}$ was disclosed. Overlying the tumour the retina was detached and the uvea was diffusely pigmented (Fig 2). The microscopic study (Fig 3) revealed a pigmented tumour composed of spindle and epithelioid cells confined to the uvea and extending to the pars plana of the ciliary body. Diffusely scattered pigmented fusiform and dendritic melanocytes were present in the optic nerve head, trabecular meshwork, sclera, episclera, and choroid.

\section{Comment}

Since the first case reported by $\mathrm{Hulke}^{3}$ in 1861, approximately 700 cases of ODM have
Figure $2 A$ histopathological specimen revealed a heavy pigmented tumour confined to the uvea extending to the pars plana of the ciliary body. At the border of the tumour
with the sclera (arrows) there is a transition between the melanocytes without atypia with the malignant melanoma (haematoxylin and eosin; whole mount). 


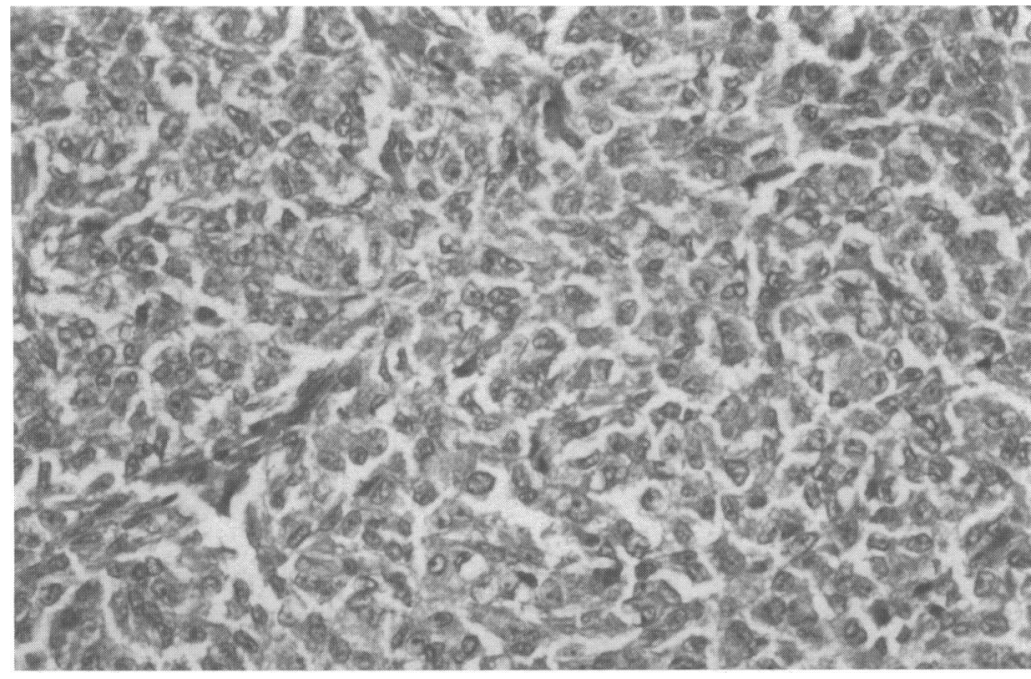

Figure 3 Microscopically the tumour revealed a mixture of malignant spindle cell and epithelioid cells (haematoxylin and eosin; magnification $\times 25$ ).

been reported in the world literature. ${ }^{4}$ The cutaneous pigmentation commonly involves the ophthalmic, maxillary, and occasionally the mandibular division of the trigeminal nerve. Oculodermal melanocytosis occurs most often in orientals and blacks and is rarely seen in the white population. ${ }^{2-7}$ In contrast, malignant melanoma transformation associated with ODM and OM is known to occur more often in whites and rarely among blacks and orientals. $^{5-9}$ The rarity of black patients reported with ODM and choroidal melanoma is supported by only two previous case reports: Nik et $a l^{7}$ reported a case of a 44-year-old black woman with a mixed cell type melanoma and ODM. Velazquez ${ }^{9}$ reported a 40 -year-old black woman with bilateral ODM with a mixed cell malignant melanoma occurring in the more heavily pigmented eye (right eye).

Diagnosis of ODM in a black patient may be difficult. The dermal pigment may be difficult to detect because of the dark skin pigmentation and the ocular involvement may be confused with racial melanosis. In a situation with unilateral hyperpigmentation of the ocular tissues, the discrepancy between racial melanosis may be easier. With careful history and physical examination, the dermal pigment may be noticed.

1 Ota M. Naevus fusco-caeruleus ophthalmo-maxillaris. Tokyo Med f 1939; 63: 1243-5.

2 Fitzpatrick TB, Zeller R, Kukita A, Kitamura H. Ocular and dermal melanocytosis. Arch Ophthalmol 1956; 56: $830-2$.

3 Hulke JW. A series of cases of carcinoma of the eyeball. Royal London Ophthalmic Hospital Reports 1861; 3: 279-86.

4 Teekhasaenee C, Ritch R, Rutnin U, Leelawongs N. Ocular findings in oculodermal melanocytosis. Arch Ophthalmol 1990; 108: 1114-20.

5 Dutton J, Anderson RL, Schelper RL, Purcell JJ, Tse DT. Orbital malignant melanoma and oculodermal melanocytosis: report of two cases and review of the literature. Ophthalmology 1984; 91: 497-507.

6 Cowan TH, Balistocky $M$. The nevus of Ota or oculodermal melanocytosis: the ocular changes. Arch Ophthalmol 1961; 65: 483-92.

7 Nik NA, Glew WB, Zimmerman LE. Malignant melanoma of the choroid in the nevus of Ota of a black patient. Arch Ophthalmol 1982; 100: 1641-3.

8 Wilkes TD, Uthman EO, Thornton CN, Cole RE. Malignant melanoma of the orbit in a black patient with ocular melanocytosis. Arch Ophthalmol 1984; 102: 904-6.

9 Velazquez N, Jones IS. Ocular and oculodermal melanocytosis associated with uveal melanoma. Ophthalmology 1983; 90: $1472-6$.

\author{
Department of \\ Ophthalmology, \\ Newcastle General \\ Hospital, Westgate \\ Road, Newcastle upon \\ Tyne NE4 6BE \\ S K Webber

\section{Sunderland Eye Infirmary, Queen Alexandra Road, Sunderland SR2 9HP C N J McGhee} \\ Department of \\ Anatomy and Human \\ Biology, The \\ University of Western \\ Australia, Nedlands, \\ Perth, Western \\ Australia 6009 \\ PG McMenamin \\ Professor C N J McGhee. \\ Accepted for publication \\ 20 October 1994
}

\section{Suzanne K Webber, Charles N J McGhee, Paul G McMenamin}

The retrobulbar injection of alcohol for analgesia is a useful, if infrequently used, tool in our therapeutic armoury for those with blind, painful eyes in which enucleation is refused or inadvisable. It is our practice to perform a preliminary retrobulbar injection with local anaesthetic which allows both the patient and the surgeon to assess the potential benefit of a retrobulbar alcohol injection. We report a case wherein the preliminary anaesthetic block demonstrated a potentially serious complication which we were able to avoid by adapting our injection technique.

\section{Case report}

The patient, a 54-year-old woman, was referred with a blind, painful right eye following a course of radiotherapy for a maxil- lary antrum carcinoma. Conservative treatment with oral analgesia and topical lubricants failed to control the ocular pain and it was concluded that a retrobulbar alcohol injection should be performed. A preliminary injection of $5 \mathrm{ml} 0.75 \%$ bupivacaine was administered using a 25 gauge $40 \mathrm{~mm}$ straight Atkinson retrobulbar needle (code no 1275, Steriseal, Redditch, England). The surgeon noted that the orbital tissues resisted the passage of the retrobulbar needle. The following day the patient reported beneficial ocular analgesia lasting several hours; however, she also observed that the 'whole' of the right side of her face had also been 'numbed'.

The injection was repeated and again the surgeon noted a stiffness of the orbital tissues which was sufficient to prevent the usually smooth unrestricted course of the needle 